OPEN ACCESS

Edited by: Patrizia Falabella,

University of Basilicata, Italy

Reviewed by:

Raúl Alberto Laumann,

Embrapa Genetic Resources and

Biotechnology, Brazil

Tania Zaviezo,

Pontifical Catholic University of Chile,

Chile

*Correspondence:

Eric Conti

eric.conti@unipg.it

Specialty section:

This article was submitted to Invertebrate Physiology,

a section of the journal

Frontiers in Physiology

Received: 14 December 2018

Accepted: 31 May 2019

Published: 04 July 2019

Citation:

Bertoldi V, Rondoni G, Brodeur J and Conti E (2019) An Egg Parasitoid

Efficiently Exploits Cues From

a Coevolved Host But Not Those From a Novel Host.

Front. Physiol. 10:746.

doi: 10.3389/fphys.2019.00746

\section{An Egg Parasitoid Efficiently Exploits Cues From a Coevolved Host But Not Those From a Novel Host}

\author{
Valeria Bertoldi ${ }^{1,2}$, Gabriele Rondoni ${ }^{1,2}$, Jacques Brodeur ${ }^{2}$ and Eric Conti ${ }^{1,2 *}$ \\ 'Dipartimento di Scienze Agrarie, Alimentari ed Ambientali, Università degli Studi di Perugia, Perugia, Italy, ${ }^{2}$ Département de \\ Sciences Biologiques, Institut de Recherche en Biologie Végétale, Université de Montréal, Montréal, QC, Canada
}

Egg parasitoids have evolved adaptations to exploit host-associated cues, especially oviposition-induced plant volatiles and odors of gravid females, when foraging for hosts. The entire host selection process is critical for successful parasitism and relevant in defining host specificity of parasitoids. We hypothesized that naïve egg parasitoid females reared on their coevolved host are able to exploit cues related to the coevolved host but not those from a novel host. We used the egg parasitoid Trissolcus japonicus, its coevolved host Halyomorpha halys, and the non-coevolved host Podisus maculiventris to evaluate this hypothesis. H. halys, a polyphagous pest native from Eastern Asia, has invaded North America and Europe, resulting in serious damage to crops. T. japonicus is the most effective egg parasitoid of $H$. halys in its native area and thus considered a major candidate for biological control. This parasitoid was detected in North America and Europe as a result of accidental introductions. Laboratory host range of $T$. japonicus includes $P$. maculiventris, an American predatory stink bug used as a biological control agent of several pests. Using T. japonicus reared on its natural host $H$. halys, we tested in a Y-tube olfactometer the responses of naive parasitoid females to volatiles from tomato plants with a deposited egg mass and feeding punctures of either $H$. halys or $P$. maculiventris. Additionally, using two different olfactometer set-ups, we tested T. japonicus responses to volatiles emitted by eggs and mature males and females of $H$. halys or $P$. maculiventris. Tomato plants subjected to oviposition and feeding by $H$. halys were preferred by the wasp compared to clean plants, suggesting a possible activation of an indirect defense mechanism. Furthermore, T. japonicus females were attracted by cues from gravid females and mature males of $H$. halys but not from eggs. By contrast, naive parasitoid females never responded to cues associated with $P$. maculiventris, although this non-target host is suitable for complete parasitoid development. Such lack of responses might reduce the probability of $T$. japonicus locating and parasitizing $P$. maculiventris under field conditions. Our experimental approach properly simulates the parasitoid host-location process and could be combined with the required host specificity tests for risk assessment in biological control programs.

Keywords: Trissolcus japonicus, invasive species, Halyomorpha halys, herbivore-induced plant volatiles, predator, Podisus maculiventris, biological control 


\section{INTRODUCTION}

Efficient exploitation of host-associated cues is a key feature for successful reproduction in insect parasitoids that need to invest their limited time on the location and parasitization of suitable hosts (Godfray, 1994; Vinson, 1998). This foraging process is especially challenging for egg parasitoids because their inactive and often inconspicuous hosts are hardly perceived from a distance (Vinson, 1998; Fatouros et al., 2008; Colazza et al., 2010). Egg parasitoid females have thus evolved adaptations to exploit host-related cues that are highly detectable and reliable indicators of the presence of suitable hosts, such as oviposition-induced plant volatiles and volatiles from gravid host females but also less reliable cues from males and nymphs (Hilker and Meiners, 2006; Conti and Colazza, 2012; Hilker and Fatouros, 2015).

In spite of such highly specialized adaptations, egg parasitoids often show a relatively wide host range, attacking species belonging to a given or related families, or even to different orders, on different plant species (Chantarasa-ard et al., 1984; Mansfield and Mills, 2002; Conti et al., 2004; Salerno et al., 2006; Zhang et al., 2011). Thus, foraging egg parasitoids can exploit different combinations of host-associated cues (Lewis et al., 1982; Vet and Groenewold, 1990; Turlings et al., 1993; Meiners and Hilker, 2000; Peñaflor et al., 2011). Alternatively, the nature of induced plant volatiles might be similar among different plant species, especially when plants belong to the same family (Colazza et al., 2004a,b; Mumm and Dicke, 2010).

Parasitoid host range may appear even wider under laboratory conditions, as some species show the capability to parasitize and develop within species that are not their natural hosts (Barratt et al., 1997; Babendreier et al., 2003). This aspect is interesting from an applied perspective since it allows rearing biocontrol agents on factitious hosts (Hoffmann et al., 2001; Cônsoli and Grenier, 2010) and consents the establishment of novel associations (Wyckhuys et al., 2009; Henry et al., 2010). On the other hand, this can be a limitation to classical biological control due to the apparently wide host range shown by these parasitoids in host-specificity tests, thus suggesting a risk that the candidate biocontrol agent may attack non-target species (Barron et al., 2003; Louda et al., 2003; Girod et al., 2018).

However, how high is the probability that, under field conditions, parasitoids would find and, subsequently, successfully parasitize non-target hosts? Considering that parasitoid host range is shaped not only by host recognition, acceptance, and suitability, but by the entire selection process, the role played by host-related cues in defining host specificity is relevant (Conti et al., 2004; Salerno et al., 2006). Exotic host species provide suitable models to examine the role of host selection cues in parasitoid host specificity. When an exotic herbivorous insect enters a new environment, multiple novel interactions may be established with native species, involving different trophic levels and resulting in unpredictable ecological consequences. From one side, native parasitoids (and other natural enemies) may adapt to the novel host, whereas from the other side, the invading species might disrupt the native trophic systems with possible negative consequences on natural control of native pest populations (Fand et al., 2013; Harvey, 2015; Martorana et al., 2017).

A relevant example is that of the brown marmorated stink bug (BMSB), Halyomorpha halys Stål (Hemiptera: Pentatomidae). Native to Eastern Asia, H. halys was first recorded in North America in 2003 (Hoebeke and Carter, 2003) and in Europe in 2004 (Wermelinger et al., 2008; Arnold, 2009; Haye et al., 2014). Since then $H$. halys has spread over the two continents and, because of its high polyphagy and capacity to build up large populations, it is causing serious damage to many agricultural systems (Hoebeke and Carter, 2003; Lee et al., 2013). In both invaded continents, several indigenous parasitoids and predators exploit the invasive herbivore, although their efficacy is generally low (Rice et al., 2014; Abram et al., 2015; Haye et al., 2015; Cornelius et al., 2016; Herlihy et al., 2016; Roversi et al., 2017; Costi et al., 2018; Morrison et al., 2018; Stahl, 2018). Interestingly, two native European parasitoids were found to be attracted to plant volatiles induced by oviposition of $H$. halys and to volatiles from males, which might be related to the low host specificity of these parasitoids (Rondoni et al., 2017). However, it has been documented both in America and Europe that $H$. halys may also act as an "evolutionary trap" for some native parasitoid species, which readily accept stink bug eggs as host but cannot successfully develop (Abram et al., 2014; Haye et al., 2015; Konopka et al., 2018). Additionally, $H$. halys may disrupt semiochemical networks, thus affecting the efficacy of local parasitoids (Martorana et al., 2017).

Therefore, in addition to relying on new associations with native parasitoids for control of $H$. halys, the introduction of coevolved parasitoids from the native area of the pest, in Asia, might be also considered. Trissolcus japonicus (Ashmead) (Hymenoptera: Scelionidae) is the dominant egg parasitoid of $H$. halys in its native area, with high parasitism rates (60-90\%), and a candidate for biological control (Qiu et al., 2007; Yang et al., 2009; Dieckhoff et al., 2017). Nevertheless, its relatively large host range in Asia, together with results from host specificity tests indicating its ability to attack several Pentatomoidea species, are of concern to biocontrol practitioners (Haye et al., 2014; Lara et al., 2016; Matsuo et al., 2016; Hedstrom et al., 2017; Botch and Delfosse, 2018). Noticeably, the host range of T. japonicus in North America also includes Podisus maculiventris (Say) (Hemiptera: Pentatomidae) (Hedstrom et al., 2017; Botch and Delfosse, 2018), a predator of several insect pests including $H$. halys (Pote and Nielsen, 2017). When reared on $H$. halys eggs, $T$. japonicus showed a strong preference for its associated host (Botch and Delfosse, 2018). However, when reared on non-target hosts, this parasitoid showed reduced host-specificity, although a trade-off was observed in terms of reduced brood size and fertility, suggesting specialization to the coevolved host (Botch and Delfosse, 2018).

Because of such risks of non-target effects, T. japonicus has not yet been released in the field for biological control. In spite of that, this parasitoid is now present both in North America (Talamas et al., 2015; Milnes et al., 2016; Hedstrom et al., 2017; Morrison et al., 2018; Abram et al., 2019) and Europe (Stahl et al., 2018), likely as a consequence of accidental introductions (Milnes et al., 2016). 
Therefore, it would be important to, first, confirm that T. japonicus exploits reliable volatile cues associated with its natural host $H$. halys and, second, determine if the parasitoid can also exploit cues associated with non-target $P$. maculiventris. It cannot be ruled out that the parasitoid could respond to cues from non-coevolved hosts as a consequence of learning (Giunti et al., 2015) or conditioning by rearing host (Godfray, 2007; Botch and Delfosse, 2018). However, our investigation is focused on naïve parasitoids reared on their naturally associated host $H$. halys. This species reliably represents the most available host for T. japonicus under field conditions in the invaded areas, where the population density of $H$. halys might be higher compared to that of the predatory stink bug $P$. maculiventris.

Here, we carried out olfactometer bioassays to test the following hypotheses: (1) naïv T. japonicus females have the innate capacity to efficiently exploit $H$. halys kairomones and oviposition-induced plant synomones and (2) although T. japonicus was shown to accept and develop in P. maculiventris eggs in the laboratory, naive females reared on $H$. halys do not respond to cues associated with this new host because of lack of coevolution and learning experience. Using two types of Y-tube olfactometer set-ups (long- and close-distance assays), we tested the parasitoid response to plant and host volatiles, associated with $H$. halys and P. maculiventris.

\section{MATERIALS AND METHODS}

\section{Insect Rearing}

Adults of $H$. halys were originally collected from a population in Hamilton (Ontario, Canada) in 2012 and reared continuously thereafter in nylon ventilated cages $\left(30 \mathrm{~cm}^{3}\right)$ with raw pumpkin seeds, carrots, green beans, grapes, and potted soybean plants, at $24 \pm 1^{\circ} \mathrm{C}, 50 \pm 5 \%$ relative humidity and a $16: 8 \mathrm{~h}$ light:dark photoperiod. Eggs of $H$. halys were collected every 2 days and transferred to new cages to maintain the colony or used for parasitoid rearing. Eggs laid on the sides of the cages were collected daily for experiments.

Adults of $P$. maculiventris were originally collected from several locations in London and Ottawa (Ontario, Canada) regions in 2011 and 2012 and partly pooled with individuals provided from a greenhouse supply company (Anatis Bioprotection, Canada). Adults were fed with live mealworm larvae, Tenebrio molitor L. (Coleoptera: Tenebrionidae), fresh green beans, and bean plants, and reared in nylon cages at $24 \pm 1{ }^{\circ} \mathrm{C}, 50 \pm 5 \%$ relative humidity and a $16: 8 \mathrm{~h}$ light:dark photoperiod. Previous studies showed that $P$. maculiventris commonly feeds on plant tissues, especially when prey are scarce, probably to acquire water and nutrients (Ruberson et al., 1986; Valicente and O'Neil, 1995; De Clercq, 2008). First instar larvae, which do not feed, were provided with green beans for moisture. From the second instar onward, nymphs were kept in plastic cylinders and fed with mealworm and green beans. Eggs were collected every 2 days to maintain the colony and daily, from the sides of the cages, for experiments.
T. japonicus was obtained from the Beneficial Insects Introduction Research Unit, USDA Agricultural Research Service, Newark, DE, USA in 2017. Parasitoids were kept in nylon cages $\left(30 \mathrm{~cm}^{3}\right)$ and provided with a $1: 1(\mathrm{vol} / \mathrm{vol})$ honey water solution on a small piece of ParaFilm ${ }^{\circledast}$. T. japonicus was reared on $24 \mathrm{~h}$-old $H$. halys eggs. Each week, egg masses were glued (Pritt ${ }^{\circledR}$ stick glue) on filter paper, offered to parasitoids, and then transferred to Petri dishes for parasitoid development. After emergence, male and female parasitoids were kept together for mating. For the experiments, insects were isolated in glass tubes before being tested.

\section{Plants}

Seeds of tomato (Lycopersicum esculentum Mill. cv Rio Grande) were individually sown in plastic pots $(\varnothing: 5.5-8 \mathrm{~cm}$; h: $6.5 \mathrm{~cm}$ ) filled with a mix of coarse sphagnum peat moss and perlite (Berger BM 6 soil). Plants were maintained in a climatic chamber $\left(24 \pm 2^{\circ} \mathrm{C}, 70 \pm 5 \% \mathrm{RH}, 12 \mathrm{~h}: 12 \mathrm{~h} \mathrm{~L} / \mathrm{D}\right)$ and irrigated every 3 days. A soluble mixture fertilizer (PlantProd $15 \mathrm{~N}-30 \mathrm{P}-15 \mathrm{~K})$ was added 1 week after germination. Plants 3-4 weeks old were used for the olfactometer assays.

\section{Plant Volatiles}

Tomato plants used as a source of volatiles in bioassays were exposed to a reproductive stink bug female of either $H$. halys or $P$. maculiventris. The pentatomid female was placed in a clip cage for 24-72 $\mathrm{h}$ and allowed to feed and oviposit on the plant. Plants were regularly checked for finding egg masses, and the female was removed after egg detection on the abaxial leaf surface, whereas eggs were not removed to prevent mechanical damage to plant (Colazza et al., 2004a,b; Fatouros et al., 2005; Conti et al., 2010). When eggs were not found after $72 \mathrm{~h}$, the plant was considered as having being exposed to only feeding activity. To reduce feeding damage by $H$. halys on the plants and to promote oviposition, five sunflower kernels were placed in the clip cage. No prey was provided to P. maculiventris to ensure plant feeding by this predaceous stink bug. The plants were tested $24 \mathrm{~h}$ after oviposition or after the end of the exposition period $(72 \mathrm{~h})$ when there was only feeding. The four treatments were: $\mathrm{P}+\mathrm{HhFeed}$ : plants with $H$. halys feeding damage but no oviposition; $\mathrm{P}+$ HhEggs: plants with $H$. halys feeding damage and oviposition of an egg mass; P + PmFeed: plants where a $P$. maculiventris female had fed but did not oviposit; P + PmEggs: plants where a P. maculiventris female had fed and laid an egg mass. Clean tomato plants (CP) were used as control.

\section{Stink Bug Volatiles}

Volatile cues from males or females in their reproductive phase or freshly laid eggs of $H$. halys or P. maculiventris were tested in the olfactometer vs. clean air. Stink bug males were 1-2 weeks old, sexual maturity occurring about 1 week following emergence (Polajnar et al., 2016). Females were at least 1-week old and in their ovipositional phase, as evident by their physogastric abdomen (De Clercq, 2008; Polajnar et al., 2016). Four adult pentatomids (females or males) were used per bioassay, and 
adults were not fed during the assays. Tested egg masses of either $H$. halys or $P$. maculiventris were $<24 \mathrm{~h}$ old and composed of about 28 and 19 eggs, respectively, as naturally laid on the nylon sides of the rearing cages. The six treatments were volatiles from: HhFem: four $H$. halys females; HhMal: four $H$. halys males; PmFem: four P. maculiventris females; PmMal: four $P$. maculiventris males; HhEggs: a single egg mass of H. halys; and PmEggs: a single egg mass of P. maculiventris. Clean air was used in the control arm of the olfactometer against insect volatiles.

\section{Olfactometer Bioassays}

A Y-tube olfactometer, made from a glass body (stem: $80 \mathrm{~mm}$; arms: $200 \mathrm{~mm}$ at $30^{\circ}$ angle between arms; internal diameter $12 \mathrm{~mm}$; outside diameter $15 \mathrm{~mm}$ ), was used to determine the behavioral responses of female T. japonicus to host-associated cues. A stream of air from the laboratory compressed-air supply was purified by a charcoal filter made from a $500 \mathrm{ml}$ flask (Pyrex) with four layers each of alternated charcoal and fiberglass. The stream was then bubbled through water in a second $500 \mathrm{ml}$ flask (Pyrex) to humidify the air before it passed into the olfactometer. The air also passed through flow meters set in each arm at $0.5 / 0.6 \mathrm{~L} \mathrm{~min}^{-1}$. The Y-tube was held in a cardboard box, black on the sides and white on bottom, with two holes for connection with the air flow tubes, and illuminated from above by two $18-\mathrm{W}$ cool white fluorescent lamps. A thin pencil line drawn on the base of the olfactometer box at $100 \mathrm{~mm}$ from the beginning of stem divided the olfactometer into three parts: the left arm, the right arm, and the common area with the junction of the two arms.

Two different types of olfactometer setups were used: "longdistance" and "close-distance" olfactometer. In the "long-distance" setup, each air stream passed through a 4 L glass jar (Ø: 10-15 cm; $\mathrm{h}: 30 \mathrm{~cm}$ ) containing the odor source and connected to the olfactometer arm through a plastic tube (inner diameter $8 \mathrm{~mm}$ and outer diameter $12 \mathrm{~mm}$ ) of about $40 \mathrm{~cm}$ of length. For the "close-distance" setup, the source of volatiles were placed close to the olfactometer in two little chambers, each made from a modified $15 \mathrm{ml}$ falcon tube with two holes, one on the cover and one on the bottom, both closed by a brass mesh. These chambers were connected with the tubes carrying the air and placed directly at the ends of the arms of the olfactometer, held with Parafilm wrapped on it. To avoid visual stimuli the chambers were kept outside from the illuminated box containing the olfactometer and in the dark. This type of set-up, similar to others used by Colazza et al. (1999), Conti et al. (2003) and Zhong et al. (2017), aimed at studying the searching behavior of the parasitoid once arrived close to the host colony. The volatiles from stink bug treated plants were tested in the "long-distance" olfactometer, whereas those from adults and eggs of $H$. halys and $P$. maculiventris were tested in both olfactometers. The rationale being that oviposition-induced plant volatiles are probably exploited from a longer range than volatiles from adult stink bugs and from eggs (Conti et al., 2003; Colazza et al., 2010; Hilker and Fatouros, 2015).

The assays were conducted from the 9:00 to 16:00, and the temperature in the bioassay room was maintained at $25^{\circ} \mathrm{C}$.
A T. japonicus female was introduced in the Y-tube at the entrance of the central stem and let move freely for $10 \mathrm{~min}$. After up to five wasps (block) had been tested, the glass olfactometer was cleaned with a laboratory detergent and rinsed with hot tap water. Moreover, the tubes connecting the plants to each of the Y-tube arms were switched to avoid bias. All tested wasps were naïve, 3-8 days old, likely mated, and used only once. Each plant, group of adults or egg masses were used for a set of up to 10 bioassays, each carried out with different parasitoid females. For each treatment, 29-77 replicates were conducted. Overall, only five insects did not respond, i.e., they stayed in the common stem, and were removed from the analysis. The parasitoid's residence time, i.e., the durations and frequency of their presence in each olfactometer arm and in the common stem, was recorded using JWatcher 1.0 (Blumstein et al., 2006).

\section{Data Analyses}

For each treatment, percent residence time was calculated as the proportion of time spent in the treatment arm on the total time spent in both arms (i.e., excluding the time spent in the common stem). Percent data were normalized using arcsine square root transformation. Generalized linear models (GLMs, Gaussian error distribution) were fitted to test the attraction of $T$. japonicus females to the different sources of volatiles against clean air or clean plant (Zuur et al., 2009). The effect of blocks was initially included as a random effect in generalized mixed models, but its relevance, evaluated by means of likelihood ratio test, was never justified (Zuur et al., 2009). All analyses were run under R statistical environment (R Core Team, 2014).

\section{RESULTS}

\section{"Long-Distance" Assays}

Females T. japonicus responded to volatiles from tomato plants with feeding damage and an egg mass of $H$. halys $(\mathrm{P}+$ HhEggs vs. CP: $p=0.0013)$ but not to volatiles from plants with only feeding punctures by $H$. halys $(\mathrm{P}+$ HhFeed vs. CP: $p=0.382$ ) (Figure 1). In contrast, parasitoid females did not respond to volatiles from plants with feeding damage and an egg mass of $P$. maculiventris $(\mathrm{P}+$ PmEggs vs. $\mathrm{CP}$ : $p=0.522$ ). However, they seemed to be repelled by plants subjected only to feeding by $P$. maculiventris although the results were barely non-significant $(\mathrm{P}+\mathrm{PmFeed}$ vs. $\mathrm{CP}$ : $p=0.0567)$. Finally, the parasitoids did not show a preference for clean control plants or clean air (CP vs. Air: $p=0.659$ ) (Figure 1).

Parasitoid females did not respond in the "long-distance" olfactometer setup to volatiles emitted by $H$. halys eggs (HhEggs vs. Air: $p=0.258$ ), gravid females (HhFem vs. Air: $p=0.119$ ) or reproductive males (HhMal vs. Air: $p=0.848$ ). Similarly, the parasitoid was not attracted to volatiles from $P$. maculiventris (PmEggs vs. Air: $p=0.407$; PmFem vs. Air: $p=0.297$; PmMal vs. Air: $p=0.090$ ) (Figure 2). 


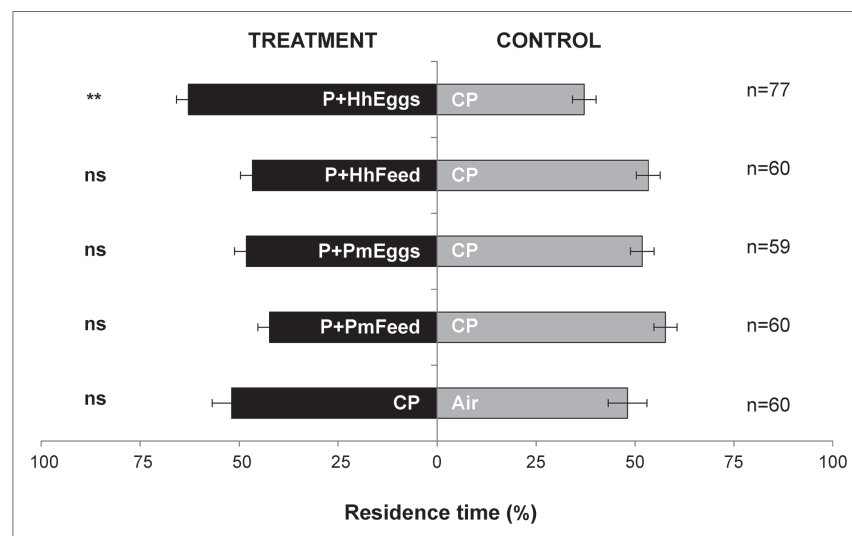

FIGURE 1 | Residence time (mean percentage \pm SE) of Trissolcus japonicus females in the treatment vs. control arm of a Y-tube olfactometer designed for "long-distance" assays. Treatments were volatiles from tomato plants, where: a Halyomorpha halys female had fed and oviposited ( $\mathrm{P}+\mathrm{H}$ hEggs); a $\mathrm{H}$. halys female had fed but did not oviposit $(\mathrm{P}+\mathrm{HhFeed}) ; \mathrm{a}$ Podisus maculiventris female had fed and oviposited (P+PmEggs); a P. maculiventris female had fed but did not oviposit ( + +PmFeed). Volatiles from clean tomato plants were used as controls $(\mathrm{CP})$. Data were analyzed by means of GLMs ( ${ }^{\star \star} P<0.01$; ns: not significant).

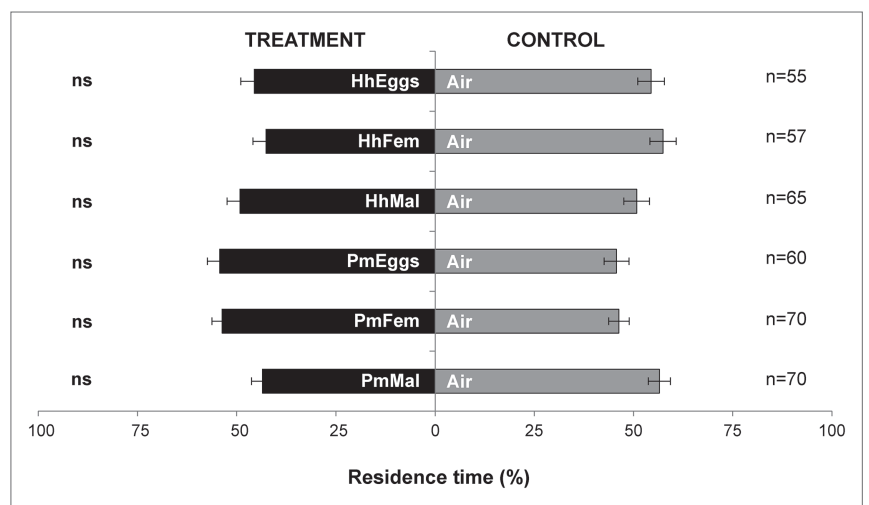

FIGURE 2 | Residence time (mean percentage \pm SE) of Trissolcus japonicus females in the treatment vs. control arm of a Y-tube olfactometer designed for "long-distance" assays. Treatments were volatiles of: a single egg mass of Halyomorpha halys (HhEggs); H. halys gravid females (HhFem); H. halys mature males (HhMal); a single egg mass of Podisus maculiventris (PmEggs); P. maculiventris gravid females (PmFem); P. maculiventris mated males (PmMal). Air was used as control (Air). Data were analyzed by means GLMs (ns: not significant).

\section{"Close-Distance" Assays}

Females of $T$. japonicus were not attracted in the "closedistance" olfactometer setup to volatiles from $H$. halys eggs (HhEggs vs. Air: $p=0.356$ ). In contrast, they significantly responded to cues from $H$. halys gravid females (HhFem vs. Air: $p=0.0052$ ) and mature males (HhMal vs. Air: $p=0.0487$ ). However, T. japonicus females never responded to $P$. maculiventris in the "close-distance" olfactometer setup (PmEggs vs. Air: $p=0.439$; PmFem vs. Air: $p=0.129$; PmMal vs. Air: $p=0.620$ ) (Figure 3).

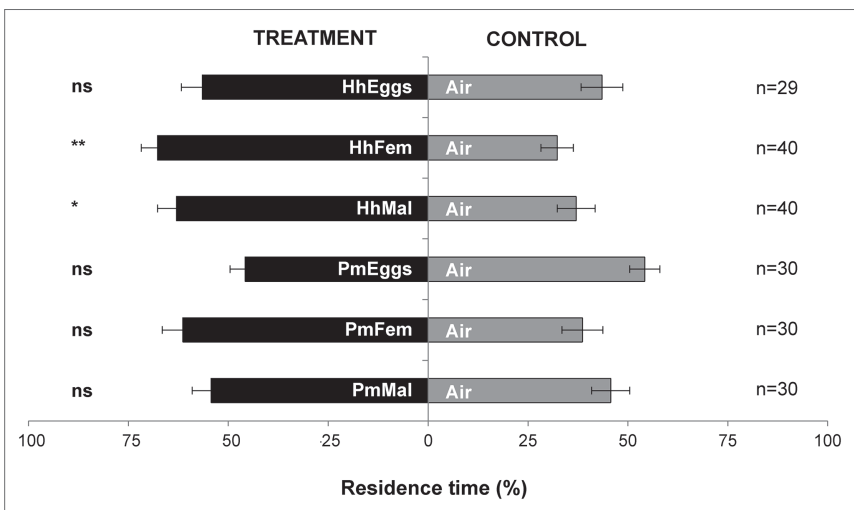

FIGURE 3 | Residence time (mean percentage \pm SE) of Trissolcus japonicus females in the treatment vs. control arm of a Y-tube olfactometer designed for "close-distance" assays. Treatments were volatiles of: a single egg mass of Halyomorpha halys (HhEggs); H. halys gravid females (HhFem); H. halys males (HhMal); a single egg mass of Podisus maculiventris (PmEggs);

P. maculiventris gravid females (PmFem); P. maculiventris males (PmMal). Air was used as control (Air). Data were analyzed by means of GLMs $\left({ }^{* \star} p<0.01\right.$; ${ }^{*} p<0.05$; ns: not significant).

\section{DISCUSSION}

Here, we demonstrated using "long-distance" olfactometer assays that naïve females of the egg parasitoid T. japonicus, reared from its coevolved host $H$. halys, positively respond to volatiles emitted by tomato plants being fed upon and bearing an egg mass of $H$. halys. Using "close-distance" olfactometer assays, we showed that the parasitoids have the capacity to detect and positively respond to cues associated with gravid females and mature males of $H$. halys. In contrast, naïve $T$. japonicus females reared on $H$. halys did not respond to any of the eight treatments involving odors associated with $P$. maculiventris. These results confirm our hypothesis about the capacity of the naïve egg parasitoid, reared on $H$. halys, to exploit cues related to its coevolved host but not those related to the novel association. However, we cannot exclude that experienced parasitoid females or those reared on P. maculiventris may also respond to cues from this novel host (Tognon et al., 2014, 2018; Botch and Delfosse, 2018). Additionally, in the "close-distance" setup, the parasitoid showed an apparently similar response to $P$. maculiventris females and $H$. halys males; thus we cannot exclude that a higher number of replications in the former would have resulted in significant values.

The ability of T. japonicus to exploit plant volatiles associated with $H$. halys eggs may be consistent with previous findings on host selection strategies developed by egg parasitoids in general and, more specifically, those attacking pentatomids (reviewed by Conti and Colazza, 2012), although we cannot exclude parasitoid response to a combination of plant and egg volatiles rather than just plant volatiles. An "early herbivore alert" (sensu Hilker and Meiners, 2006) by the plant denotes a particular type of indirect induced defense that has been observed in several other systems (Colazza et al., 2004a; Conti et al., 2010; Peñaflor et al., 2011). In our experiments, tomato plants subjected to $H$. halys oviposition and feeding were preferred over clean plants by females of T. japonicus in olfactometer assays, whereas those subjected only 
to feeding were not. Similarly, in a different system, Trissolcus basalis (Wollaston) responded to leguminous plants on which $N$. viridula had fed and oviposited compared to control plants, but not to plants on which the host only had fed (Colazza et al., 2004a). The emission of volatiles from leguminous plants was systemic, thus maximizing the release surface and synomone volatilization; additionally, the synomone activity was tuned to parasitoid behavior since preference was higher toward fresh eggs and faded for older eggs that were not suitable for parasitoid development (Colazza et al., 2004a). Chemical analyses of the emitted volatiles showed an increase of (E)- $\beta$-caryophyllene (Colazza et al., 2004b). However, of significance, tomato plants that have been used in our system are not native from Asia, although their cultivation has spread worldwide from America in the 16th century, including Eastern China. Thus, tomato defensive responses to $H$. halys may be quite general, against several species, or might result from plant adaptation, although further investigations may provide different explanations.

Interestingly, previous papers showed responses of different parasitoids to volatiles emitted by the plant-herbivore complex and the activation of plant defenses against $H$. halys (Rondoni et al., 2017, 2018). Specifically, the egg parasitoids Anastatus bifasciatus (Geoffroy) (Hymenoptera: Eupelmidae) and Ooencyrtus telenomicida (Vassiliev) (Hymenoptera: Encyrtidae) positively responded in an olfactometer to volatiles emitted by faba bean plants with oviposition and feeding punctures of $H$. halys and to volatiles from males (Rondoni et al., 2017). Considering that T. basalis did not react to $H$. halys induced plant volatiles, exploitation of plant volatiles in this system most likely depends on parasitoid host range, which is much wider for A. bifasciatus and O. telenomicida compared to T. basalis (Rondoni et al., 2017). Thus, complex combinations of indirect (Rondoni et al., 2017) and direct (Rondoni et al., 2018) defense strategies can be activated by plants against invasive herbivore species, suggesting possible existence of general (non-specific), conserved plant defensive mechanisms. One of our olfactometer set-ups for the plant volatile assays tentatively simulated a long-range diffusion of the chemical blend from plants. T. japonicus response seems thus consistent with general hypothesis that induced-plant volatiles act as long-distance attractants (Vet and Dicke, 1992; Hilker and Fatouros, 2015), although this is not always the case since in different systems female egg parasitoids only respond to oviposition-induced plant volatiles from a very short distance in static olfactometer (Fatouros et al., 2005, 2009; Conti et al., 2010). Therefore, additive effects from different cues, originated from host and plant, are worth being investigated for T. japonicus on plants attacked by $H$. halys.

In our experiments, T. japonicus also responded to cues from gravid females and sexually mature males of $H$. halys, but only when using the "close-distance" olfactometer set up, with the volatile sources at the end of the olfactometer arm, whereas it did not respond to host odors in the "long-distance" setup. The reason for these different responses is not clear and possibly depends on the different distance of source from the olfactometer, different concentrations of chemical volatiles or emissions of volatile blends based on the different container sizes and insect crowding conditions, or on a combination of these and other factors. The chemical ecology of $H$. halys has been intensely studied and several compounds have been identified (Khrimian et al., 2014; Harris et al., 2015; Weber et al., 2017; Nixon et al., 2018). Zhong et al. (2017) found that females of T. japonicus were attracted in Y-tube assays by n-tridecane, a component of the $H$. halys defensive secretion, and that treatment with this compound significantly improved host-searching efficiency of female T. japonicus. By contrast, (E)-2-decenal, also a defensive secretion, was strongly repellent to the parasitoid (Zhong et al., 2017). Therefore, additional investigation will be necessary to understand the role of host-derived cues acting on a short range in host location by $T$. japonicus, including possible vibrational cues from $H$. halys adults, as was shown for other egg parasitoids associated with stink bugs (Laumann et al., 2007, 2011).

Detection of host eggs by parasitoids is more difficult than for larval or adult hosts, as eggs emit small amounts of volatiles, mostly useful as short-range cues (Vet et al., 1995; Vinson, 1998). Accordingly, we did not observe any preference for volatiles from a single egg mass of $H$. halys in the bioassays. This also suggests that $T$. japonicus response to plants with $H$. halys eggs was due to the volatiles emitted from plants as a consequence of oviposition, although it cannot be excluded that the parasitoid is attracted by a combination of both plant and egg volatiles. However, while visual cues may have a role when the parasitoid is close to the egg mass (Sugimoto et al., 1988), they do not appear crucial for egg location, whereas very short-range volatile kairomones from eggs are considered more important, as shown for the egg parasitoid T. brochymenae on M. histrionica (Conti et al., 2003).

The lack of response by $T$. japonicus to volatiles from any treatments involving $P$. maculiventris, although it was expected from a coevolutionary and behavioral/learning perspective, still needs to be explained from a semiochemical perspective. $P$. maculiventris is a predatory stink bug that also feeds on plant tissues (Ruberson et al., 1986; Valicente and O'Neil, 1995), but no evidence of feeding damage is reported (De Clercq, 2008). In laboratory conditions, $P$. maculiventris often landed on tomato plants to lay eggs and feed (Bertoldi, personal observations). Intriguingly, in our olfactometer observations, tomato plants subjected to feeding by $P$. maculiventris but without oviposition seemed to be almost repellent toward T. japonicus. One may consider that plants have the ability to discriminate between herbivorous and predaceous stink bugs and thus emit synomones only when attacked by herbivores, but no data support this speculation. In any case, it seems that oviposition and feeding activity of $P$. maculiventris did not activate the plant indirect defenses or that the parasitoid is not attracted to the combination of volatiles from plant and $P$. maculiventris eggs.

Concerning treatments with only volatiles associated with reproductive females or males of $P$. maculiventris, naïve T. japonicus females reared from $H$. halys eggs did not respond in either types of olfactometer. This absence of innate response is not surprising, because of the lack of coevolution of the novel host-parasitoid association, and may be explained by the $P$. maculiventris volatiles, which are mostly different from those of $H$. halys (Aldrich et al., 1984; Kitamura et al., 1984; Harris et al., 2015; Zhong et al., 2017). 
From an applied perspective, our results are interesting in the context of $T$. japonicus being the most effective parasitoid of H. halys in its native area (Yang et al., 2009; Dieckhoff et al., 2017), as well as a candidate for classical biological control against $H$. halys in newly invaded areas. This parasitoid shows a number of positive attributes, such as high parasitism rate in the field (Qiu et al., 2007; Talamas et al., 2013), short developmental time (Yang et al., 2009), cold tolerance (Santacruz et al., 2017), and climate suitability (Avila and Charles, 2018).

In spite of the concerns raised by the large host range of T. japonicus, which involves several stink bug species including P. maculiventris (Haye et al., 2014; Matsuo et al., 2016; Hedstrom et al., 2017; Botch and Delfosse, 2018), our results suggest that the probability for $P$. maculiventris to be located by the exotic parasitoid in the field would be low; T. japonicus will mainly respond to volatile cues from $H$. halys. This should limit parasitism risk to $P$. maculiventris and potentially to other native Pentatomid species, although it might be possible for $T$. japonicus to detect and parasitize $P$. maculiventris especially where $H$. halys co-exist with other Pentatomidae. Additionally, T. japonicus was shown to adapt to new hosts or learn to respond to its odor and after that become more prone to choose the new host, reducing its specificity, although there is a cost for such adaptation (Botch and Delfosse, 2018). The effect of the rearing host on parasitoid behavior was also described for other species (Godfray, 2007; Tognon et al., 2014, 2018). Further studies are therefore required to evaluate the physiological and the ecological host range of T. japonicus in the areas of introduction and to evaluate the possible effects of adaptation to the new

\section{REFERENCES}

Abram, P. K., Doyon, J., Brodeur, J., Gariepy, T. D., and Boivin, G. (2015). Susceptibility of Halyomorpha halys (Hemiptera: Pentatomidae) eggs to different life stages of three generalist predators. Can. Entomol. 147, 222-226. doi: $10.4039 /$ tce.2014.41

Abram, P. K., Gariepy, T. D., Boivin, G., and Brodeur, J. (2014). An invasive stink bug as an evolutionary trap for an indigenous egg parasitoid. Biol. Invasions 16, 1387-1395. doi: 10.1007/s10530-013-0576-y

Abram, P. K., Talamas, E. J., Acheampong, S., Mason, P. G., and Gariepy, T. D. (2019). First detection of the samurai wasp, Trissolcus japonicus (Ashmead) (Hymenoptera, Scelionidae), in Canada. J. Hymenopt. Res. 68, 29-36. doi: 10.3897/jhr.68.32203

Aldrich, J. R., Kochansky, J. P., Lusby, W. R., and Sexton, J. D. (1984). Semiochemicals from a predaceous stink bug, Podisus maculiventris (Hemiptera: Pentatomidae). J. Wash. Acad. Sci. 74, 39-46.

Arnold, K. (2009). Halyomorpha halys (Stål, 1855), eine für die europäische fauna neu nachgewiesene wanzenart (Insecta: Heteroptera: Pentatomidae: Cappaeini). Mitt Thüringer Entomol. 16:19.

Avila, G. A., and Charles, J. G. (2018). Modelling the potential geographic distribution of Trissolcus japonicus: a biological control agent of the brown marmorated stink bug, Halyomorpha halys. BioControl 63, 505-518. doi: 10.1007/s10526-018-9866-8

Babendreier, D., Kuske, S., and Bigler, F. (2003). Non-target host acceptance and parasitism by Trichogramma brassicae Bezdenko (Hymenoptera: Trichogrammatidae) in the laboratory. Biol. Control 26, 128-138. doi: 10.1016/ S1049-9644(02)00121-4

Barratt, B. I. P., Evans, A. A., Ferguson, C. M., Barker, G. M., McNeill, M. R., and Phillips, C. B. (1997). Laboratory nontarget host range of the introduced parasitoids Microctonus aethiopoides and M. hyperodae (Hymenoptera: host on the parasitoid ability to exploit host associated volatiles. Testing parasitoid responses to host cues, whether they are newly introduced or candidate for released in biological control programs, would help to predict possible non-target effects. We think that this approach could be complementary to standard host-specificity tests because it examines different host selection steps resulting in a given host-parasitoid association.

\section{AUTHOR CONTRIBUTIONS}

$\mathrm{VB}, \mathrm{GR}, \mathrm{JB}$, and EC conceived and designed the experiments. $\mathrm{VB}$ and GR performed the experiments and analyzed the data. VB, GR, JB, and EC interpreted results, drafted, and revised the article.

\section{FUNDING}

This research was supported by the Marie Skłodowska-Curie Research and Innovation Staff Exchange (RISE) H2020-MSCARISE-2015 of the European Union with the project Impact of invasive alien true bug species in native trophic webs INVASION (GA 690952).

\section{ACKNOWLEDGMENTS}

We thank Josée Doyon for insect rearing and technical assistance.
Braconidae) compared with field parasitism in New Zealand. Environ. Entomol. 26, 694-702. doi: 10.1093/ee/26.3.694

Barron, M. C., Barlow, N. D., and Wratten, S. D. (2003). Non-target parasitism of the endemic New Zealand red admiral butterfly (Bassaris gonerilla) by the introduced biological control agent Pteromalus puparum. Biol. Control 27, 329-335. doi: 10.1016/S1049-9644(03)00028-8

Blumstein, D. T., Evans, C. S., and Daniels, J. C. (2006). JWatcher (Version 1.0). Available at: http://www.jwatcher.ucla.edu (Accessed September 3, 2018).

Botch, P. S., and Delfosse, E. S. (2018). Host-acceptance behavior of Trissolcus japonicus (Hymenoptera: Scelionidae) reared on the invasive Halyomorpha halys (Heteroptera: Pentatomidae) and nontarget species. Environ. Entomol. 47, 403-411. doi: 10.1093/ee/nvy014

Chantarasa-ard, S., Hirashima, Y., and Hirao, J. (1984). Host range and host suitability of Anagrus incarnatus Haliday (Hymenoptera: Mymaridae): an egg parasitoid of Delphacid Planthoppers. Appl. Entomol. Zool. 19, 491-497. doi: 10.1303/aez.19.491

Colazza, S., Fucarino, A., Peri, E., Salerno, G., Conti, E., and Bin, F. (2004a). Insect oviposition induces volatile emission in herbaceous plants that attracts egg parasitoids. J. Exp. Biol. 207, 47-53. doi: 10.1242/jeb.00732

Colazza, S., McElfresh, J. S., and Millar, J. G. (2004b). Identification of volatile synomones, induced by Nezara viridula feeding and oviposition on bean spp., that attract the egg parasitoid Trissolcus basalis. J. Chem. Ecol. 30, 945-964. doi: 10.1023/B:JOEC.0000028460.70584.d1

Colazza, S., Peri, E., Salerno, G., and Conti, E. (2010). "Host searching by egg parasitoids: exploitation of host chemical cues" in Egg parasitoids in agroecosystems with emphasis on Trichogramma. eds. F. L. Cônsoli, J. R. P. Parra, and R. A. Zucchi (Dordrecht, NL: Springer), 97-147.

Colazza, S., Salerno, G., and Wajnberg, E. (1999). Volatile and contact chemicals released by Nezara viridula (Heteroptera: Pentatomidae) have a kairomonal 
effect on the egg parasitoid Trissolcus basalis (Hymenoptera: Scelionidae). Biol. Control 16, 310-317. doi: 10.1006/bcon.1999.0763

Cônsoli, F. L., and Grenier, S. (2010). "In vitro rearing of egg parasitoids" in Egg parasitoids in agroecosystems with emphasis on Trichogramma. eds. F. L. Cônsoli, J. R. P. Parra, and R. A. Zucchi (Netherlands, NL: Springer), 293-313.

Conti, E., and Colazza, S. (2012). Chemical ecology of egg parasitoids associated with true bugs. Psyche 2012:651015. doi: 10.1155/2012/651015

Conti, E., Salerno, G., Bin, F., and Vinson, S. B. (2004). The role of host semiochemicals in parasitoid specificity: a case study with Trissolcus brochymenae and Trissolcus simoni on pentatomid bugs. Biol. Control 29, 435-444. doi: 10.1016/j.biocontrol.2003.08.009

Conti, E., Salerno, G., Bin, F., Williams, H. J., and Vinson, S. B. (2003). Chemical cues from Murgantia histrionica eliciting host location and recognition in the egg parasitoid Trissolcus brochymenae. J. Chem. Ecol. 29, 115-130. doi: 10.1023/A:1021980614512

Conti, E., Salerno, G., Leombruni, B., Frati, F., and Bin, F. (2010). Short-range allelochemicals from a plant-herbivore association: a singular case of oviposition-induced synomone for an egg parasitoid. J. Exp. Biol. 213, 3911-3919. doi: 10.1242/jeb.045922

Cornelius, M. L., Dieckhoff, C., Hoelmer, K. A., Olsen, R. T., Weber, D. C., Herlihy, M. V., et al. (2016). Biological control of sentinel egg masses of the exotic invasive stink bug Halyomorpha halys (Stål) in Mid-Atlantic USA ornamental landscapes. Biol. Control 103, 11-20. doi: 10.1016/j.biocontrol.2016.07.011

Costi, E., Haye, T., and Maistrello, L. (2018). Surveying native egg parasitoids and predators of the invasive Halyomorpha halys in Northern Italy. J. Appl. Entomol. 143, 299-307. doi: 10.1111/jen.12590

De Clercq, P. (2008). "Spined soldier bug, Podisus maculiventris Say (Hemiptera: Pentatomidae: Asopinae)" in Encyclopedia of Entomology. Vol. 4, ed. J. L. Capinera (Heidelberg: Springer), 3508-3510.

Dieckhoff, C., Tatman, K. M., and Hoelmer, K. A. (2017). Natural biological control of Halyomorpha halys by native egg parasitoids: a multi-year survey in northern Delaware. J. Pest. Sci. 90, 1143-1158. doi: 10.1007/ s10340-017-0868-6

Fand, B. B., Suroshe, S. S., and Gautam, R. D. (2013). Fortuitous biological control of insect pests and weeds: a critical review. The Bioscan. 8, 1-10.

Fatouros, N. E., Bukovinszkine'Kiss, G., Kalkers, L. A., Gamborena, R. S., Dicke, M., and Hilker, M. (2005). Oviposition induced plant cues: do they arrest Trichogramma wasps during host location? Entomol. Exp. Appl. 115, 207-215. doi: 10.1111/j.1570-7458.2005.00245.x

Fatouros, N. E., Dicke, M., Mumm, R., Meiners, T., and Hilker, M. (2008). Foraging behavior of egg parasitoids exploiting chemical information. Behav. Ecol. 19, 677-689. doi: 10.1093/beheco/arn011

Fatouros, N. E., Pashalidou, F. G., Cordero, W. V. A., van Loon, J. J., Mumm, R., Dicke, M., et al. (2009). Anti-aphrodisiac compounds of male butterflies increase the risk of egg parasitoid attack by inducing plant synomone production. J. Chem. Ecol. 35, 1373-1381. doi: 10.1007/s10886-009-9714-5

Girod, P., Lierhmann, O., Urvois, T., Turlings, T. C., Kenis, M., and Haye, T. (2018). Host specificity of Asian parasitoids for potential classical biological control of Drosophila suzukii. J. Pest. Sci. 91, 1241-1250. doi: 10.1007/ s10340-018-1003-z

Giunti, G., Canale, A., Messing, R. H., Donati, E., Stefanini, C., Michaud, J. P., et al. (2015). Parasitoid learning: current knowledge and implications for biological control. Biol. Control 90, 208-219. doi: 10.1016/j.biocontrol.2015.06.007

Godfray, H. C. J. (1994). Parasitoids: Behavioral and evolutionary ecology. (Princeton, NJ: Princeton University Press).

Godfray, H. C. J. (2007). "Parasitoids" in Encyclopedia of Biodiversity. ed. S. A. Levin (Oxford: Elsevier).

Harris, C., Abubeker, S., Yu, M., Leskey, T., and Zhang, A. (2015). Semiochemical production and laboratory behavior response of the brown marmorated stink bug, Halyomorpha halys. PLoS One 10:11. doi: 10.1371/journal. pone. 0140876

Harvey, J. A. (2015). Conserving host-parasitoid interactions in a warming world. Curr. Opin. Insect Sci. 12, 79-85. doi: 10.1016/j.cois.2015.09.001

Haye, T., Abdallah, S., Gariepy, T., and Wyniger, D. (2014). Phenology, life table analysis and temperature requirements of the invasive brown marmorated stink bug, Halyomorpha halys, in Europe. J. Pest. Sci. 87, 407-418. doi: 10.1007/s10340-014-0560-z

Haye, T., Fischer, S., Zhang, J., and Gariepy, T. (2015). Can native egg parasitoids adopt the invasive brown marmorated stink bug, Halyomorpha halys
(Heteroptera: Pentatomidae), in Europe? J. Pest Sci 88, 693-705. doi: 10.1007/ s10340-015-0671-1

Hedstrom, C., Lowenstein, D., Andrews, H., Bai, B., and Wiman, N. (2017). Pentatomid host suitability and the discovery of introduced populations of Trissolcus japonicus in Oregon. J. Pest. Sci. 90, 1169-1179. doi: 10.1007/ s10340-017-0892-6

Henry, L. M., May, N., Acheampong, S., Gillespie, D. R., and Roitberg, B. D. (2010). Host-adapted parasitoids in biological control: does source matter? Ecol. Appl. 20, 242-250. doi: 10.1890/08-1869.1

Herlihy, M. V., Talamas, E. J., and Weber, D. C. (2016). Attack and success of native and exotic parasitoids on eggs of Halyomorpha halys in three Maryland habitats. PLoS One 11:3. doi: 10.1371/journal.pone.0150275

Hilker, M., and Fatouros, N. E. (2015). Plant responses to insect egg deposition. Annu. Rev. Entomol. 60, 493-515. doi: 10.1146/annurev-ento-010814-020620

Hilker, M., and Meiners, T. (2006). Early herbivore alert: insect eggs induce plant defence. J. Chem. Ecol. 32, 1379-1397. doi: 10.1007/s10886-006-9057-4

Hoebeke, E. R., and Carter, M. E. (2003). Halyomorpha halys (Stál)(Heteroptera: Pentatomidae): a polyphagous plant pest from Asia newly detected in North America. Proc. Entomol. Soc. Wash. 105, 225-237.

Hoffmann, M. P., Ode, P. R., Walker, D. L., Gardner, J., van Nouhuys, S., and Shelton, A. M. (2001). Performance of Trichogramma ostriniae (Hymenoptera: Trichogrammatidae) reared on factitious hosts, including the target host, Ostrinia nubilalis (Lepidoptera: Crambidae). Biol. Control 21, 1-10. doi: 10.1006/ bcon.2000.0912

Khrimian, A., Zhang, A., Weber, D. C., Ho, H. Y., Aldrich, J. R., Vermillion, K. E., et al. (2014). Discovery of the aggregation pheromone of the brown marmorated stink bug (Halyomorpha halys) through the creation of stereoisomeric libraries of 1-bisabolen-3-ols. J. Nat. Prod. 77, 1708-1717. doi: 10.1021/np5003753

Kitamura, C., Wakamura, S., and Takahashi, S. (1984). Identification and functions of ventral glands secretion of some Heteroptera. Appl. Entomol. Zool. 19, 33-41. doi: 10.1303/aez.19.33

Konopka, J. K., Poinapen, D., Gariepy, T., and McNeil, J. N. (2018). Understanding the mismatch between behaviour and development in a novel host-parasitoid association. Sci. Rep. 8:15677. doi: 10.1038/s41598-018-33756-6

Lara, J., Pickett, C., Ingels, C., Haviland, D. R., Grafton-Cardwell, E., Doll, D., et al. (2016). Biological control program is being developed for brown marmorated stink bug. Calif. Agric. 70, 15-23. doi: 10.3733/ca.v070n01p15

Laumann, R. A., Čokl, A., Lopes, A. P., Fereira, J. B., Moraes, M. C. B., and Borges, M. (2011). Silent singers are not safe: selective response of a parasitoid to substrate-borne vibratory signals of stink bugs. Anim. Behav. 82, 1175-1183. doi: $10.1016 /$ j.anbehav.2011.08.017

Laumann, R. A., Moraes, M. C. B., Čokl, A., and Borges, M. (2007). Eavesdropping on sexual vibratory signals of stink bugs (Hemiptera: Pentatomidae) by the egg parasitoid Telenomus podisi. Anim. Behav. 73, 637-649. doi: 10.1016/j. anbehav.2006.09.011

Lee, D.-H., Short, B. D., Joseph, S. V., Bergh, J. C., and Leskey, T. C. (2013). Review of the biology, ecology, and management of Halyomorpha halys (Hemiptera: Pentatomidae) in China, Japan, and the Republic of Korea. Environ. Entomol. 42, 627-641. doi: 10.1603/EN13006

Lewis, W. J., Nordlund, D. A., Gueldner, R. C., Teal, P. E. A., and Tumlinson, J. H. (1982). Kairomones and their use for management of entomophagous insects. Kairomonal activity for Trichogramma spp. of abdominal tips, excretion, and a synthetic sex pheromone blend of Heliothis zea (Boddie) moths. J. Chem. Ecol. 8, 1323-1331. doi: 10.1007/BF00987765

Louda, S. M., Pemberton, R. W., Johnson, M. T., and Follett, P. (2003). Nontarget effects-the Achilles' heel of biological control? Retrospective analyses to reduce risk associated with biocontrol introductions. Annu. Rev. Entomol. 48, 365-396. doi: 10.1146/annurev.ento.48.060402.102800

Mansfield, S., and Mills, N. J. (2002). Host egg characteristics, physiological host range, and parasitism following inundative releases of Trichogramma platneri (Hymenoptera: Trichogrammatidae) in walnut orchards. Environ. Entomol. 31, 723-731. doi: 10.1603/0046-225X-31.4.723

Martorana, L., Foti, M. C., Rondoni, G., Conti, E., Colazza, S., and Peri, E. (2017). An invasive insect herbivore disrupts plant volatile-mediated tritrophic signalling. J. Pest. Sci. 90, 1079-1085. doi: 10.1007/s10340-017-0877-5

Matsuo, K., Honda, T., Itoyama, K., Toyama, M., and Hirose, Y. (2016). Discovery of three egg parasitoid species attacking the shield bug Glaucias subpunctatus (Hemiptera: Pentatomidae). Japan. J. Appl. Entomol. Zool. 60, 43-45. doi: $10.1303 /$ jjaez.2016.43 
Meiners, T., and Hilker, M. (2000). Induction of plant synomones by oviposition of a phytophagous insect. J. Chem. Ecol. 26, 221-232. doi: 10.1023/A:1005453830961

Milnes, J. M., Wiman, N. G., Talamas, E. J., Brunner, J. F., Hoelmer, K. A., Buffington, M. L., et al. (2016). Discovery of an exotic egg parasitoid of the brown marmorated stink bug, Halyomorpha halys (Stål) in the Pacific Northwest. Proc. Entomol. Soc. Wash. 118, 466-470. doi: 10.4289/0013-8797.118.3.466

Morrison, W. R. III, Blaauw, B. R., Nielsen, A. L., Talamas, E., and Leskey, T. C. (2018). Predation and parasitism by native and exotic natural enemies of Halyomorpha halys (Stål)(Hemiptera: Pentatomidae) eggs augmented with semiochemicals and differing host stimuli. Biol. Control 121, 140-150. doi: 10.1016/j.biocontrol.2018.02.016

Mumm, R., and Dicke, M. (2010). Variation in natural plant products and the attraction of bodyguards involved in indirect plant defense. Can. J. Zool. 88, 628-667. doi: 10.1139/Z10-032

Nixon, L. J., Morrison, W. R., Rice, K. B., Brockerhoff, E. G., Leskey, T. C., Guzman, F., et al. (2018). Identification of volatiles released by diapausing brown marmorated stink bug, Halyomorpha halys (Hemiptera: Pentatomidae). PLoS One 13:1. doi: 10.1371/journal.pone.0191223

Peñaflor, M. F. G. V., Erb, M., Miranda, L. A., Werneburg, A. G., and Bento, J. M. S. (2011). Herbivore-induced plant volatiles can serve as host location cues for a generalist and a specialist egg parasitoid. J. Chem. Ecol. 37, 1304-1313. doi: 10.1007/s10886-011-0047-9

Polajnar, J., Maistrello, L., Bertarella, A., and Mazzoni, V. (2016). Vibrational communication of the brown marmorated stink bug (Halyomorpha halys). Physiol. Entomol. 41, 249-259. doi: 10.1111/phen.12150

Pote, J. M., and Nielsen, A. L. (2017). Life stage specific predation of Halyomorpha halys (Stål) by generalist predators. Biol. Control 114, 1-7. doi: 10.1016/j. biocontrol.2017.07.007

Qiu, L. F., Yang, Z. Q., and Tao, W. Q. (2007). Biology and population dynamics of Trissolcus halyomorphae. Sci. Silvae Sin. 43, 62-65. doi: 10.11707/j.1001-7488. 20071111

R Core Team (2014). R: a language and environment for statistical computing. R Foundation for Statistical Computing, Vienna.

Rice, K. B., Bergh, C. J., Bergmann, E. J., Biddinger, D. J., Dieckhoff, C., Dively, G., et al. (2014). Biology, ecology, and management of brown marmorated stink bug (Hemiptera: Pentatomidae). J. Integr. Pest Manag. 5, 1-13. doi: 10.1603/IPM14002

Rondoni, G., Bertoldi, V., Malek, R., Djelouah, K., Moretti, C., Buonaurio, R., et al. (2018). Vicia faba plants respond to oviposition by invasive Halyomorpha halys activating direct defences against offspring. J. Pest. Sci. 91, 671-679. doi: 10.1007/s10340-018-0955-3

Rondoni, G., Bertoldi, V., Malek, R., Foti, M. C., Peri, E., Maistrello, L., et al. (2017). Native egg parasitoids recorded from the invasive Halyomorpha halys successfully exploit volatiles emitted by the plant-herbivore complex. J. Pest. Sci. 90, 1087-1095. doi: 10.1007/s10340-017-0861-0

Roversi, P. F., Binazzi, F., Marianelli, L., Costi, E., Maistrello, L., and Sabbatini Peverieri, G. (2017). Searching for native egg-parasitoids of the invasive alien species Halyomorpha halys stål (Heteroptera Pentatomidae) in southern europe. Redia 99, 63-70. doi: 10.19263/REDIA-99.16.01

Ruberson, J. R., Tauber, M. J., and Tauber, C. A. (1986). Plant feeding by Podisus maculiventris (Heteroptera: Pentatomidae): effect on survival, development, and preoviposition period. Environ. Entomol. 15, 894-897. doi: 10.1093/ee/15.4.894

Salerno, G., Conti, E., Peri, E., Colazza, S., and Bin, F. (2006). Kairomone involvement in the host specificity of the egg parasitoid Trissolcus basalis (Hymenoptera: Scelionidae). Eur. J. Entomol. 103, 311-318. doi: 10.14411/eje.2006.040

Santacruz, E. N., Venette, R., Dieckhoff, C., Hoelmer, K., and Koch, R. L. (2017). Cold tolerance of Trissolcus japonicus and T. cultratus, potential biological control agents of Halyomorpha halys, the brown marmorated stink bug. Biol. Control 107, 11-20. doi: 10.1016/j.biocontrol.2017.01.004

Stahl, J. (2018). Benefits and risks of using native parasitoids for augumentative biological control of the invasive pest Halyomorpha halys in Europe. $\mathrm{PhD}$ thesis. Bremen (DE): University of Bremen.

Stahl, J., Tortorici, F., Pontini, M., Bon, M. C., Hoelmer, K., Marazzi, C., et al. (2018). First discovery of adventive populations of Trissolcus japonicus in Europe. J. Pest Sci. 1-9. doi: 10.1007/s10340-018-0969-x

Sugimoto, T., Shimono, Y., Hata, Y., Nakai, A., and Yahara, M. (1988). Foraging for patchily-distributed leaf-miners by the parasitoid, Dapsilarthra rufiventris
(Hymenoptera: Braconidae): III. Visual and acoustic cues to a close range patch-location. Appl. Entomol. Zool. 23, 113-121. doi: 10.1303/aez.23.113

Talamas, E., Buffington, M., and Hoelmer, K. (2013). New synonymy of Trissolcus halyomorphae Yang. J. Hymenopt. Res. 33, 113-117. doi: 10.3897/jhr.33.5627

Talamas, E. J., Herlihy, M. V., Dieckhoff, C., Hoelmer, K. A., Buffington, M., Bon, M. C., et al. (2015). Trissolcus japonicus (Ashmead)(Hymenoptera, Scelionidae) emerges in North America. J. Hymenopt. Res. 43, 119-128. doi: 10.3897/JHR.43.4661

Tognon, R., Sant'Ana, J., Redaelli, L. R., and Meyer, A. L. (2018). Is it possible to manipulate scelionidae wasps' preference to a target host? Neotrop. Entomol. 47, 689-697. doi: 10.1007/s13744-018-0607-6

Tognon, R., Sant'Ana, J., and Jahnke, S. M. (2014). Influence of original host on chemotaxic behaviour and parasitism in Telenomus podisi Ashmead (Hymenoptera: Platygastridae). Bull. Entomol. Res. 104, 781-787. doi: 10.1017/ S0007485314000649

Turlings, T. C., Wäckers, F. L., Vet, L. E., Lewis, W. J., and Tumlinson, J. H. (1993). "Learning of host-finding cues by hymenopterous parasitoids" in Insect learning. eds. D. R. Papaj and A. C. Lewis (Boston, MA: Springer), 51-78.

Valicente, F. H., and O'Neil, R. J. (1995). Effects of host plants and feeding regimes on selected life history characteristics of Podisus maculiventris (Say) (Heteroptera: Pentatomidae). Biol. Control 5, 449-461. doi: 10.1006/bcon.1995.1054

Vet, L. E., and Dicke, M. (1992). Ecology of infochemical use by natural enemies in a tritrophic context. Annu. Rev. Entomol. 37, 141-172. doi: 10.1146/annurev.en.37.010192.001041

Vet, L. E., and Groenewold, A. W. (1990). Semiochemicals and learning in parasitoids. J. Chem. Ecol. 16, 3119-3135. doi: 10.1007/BF00979615

Vet, L. E., Lewis, W. J., and Carde, R. T. (1995). "Parasitoid foraging and learning” in Chemical ecology of insects 2. eds. R. T. Cardé and W. J. Bell (Boston, MA: Springer), 65-101.

Vinson, S. B. (1998). The general host selection behavior of parasitoid Hymenoptera and a comparison of initial strategies utilized by larvaphagous and oophagous species. Biol. Control 11, 79-96. doi: 10.1006/bcon.1997.0601

Weber, D. C., Morrison, W. R., Khrimian, A., Rice, K. B., Leskey, T. C., Rodriguez-Saona, C., et al. (2017). Chemical ecology of Halyomorpha halys: discoveries and applications. J. Pest. Sci. 90, 989-1008. doi: 10.1007/ s10340-017-0876-6

Wermelinger, B., Wyniger, D., and Forster, B. (2008). First records of an invasive bug in Europe: Halyomorpha halys Stal (Heteroptera: Pentatomidae), a new pest on woody ornamentals and fruit trees? Mitt. Schweiz. Entomol. Ges. 81, 1-8. doi: 10.5169/seals-402954

Wyckhuys, K. A., Koch, R. L., Kula, R. R., and Heimpel, G. E. (2009). Potential exposure of a classical biological control agent of the soybean aphid, Aphis glycines, on non-target aphids in North America. Biol. Invasions 11, 857-871. doi: 10.1007/s10530-008-9299-X

Yang, Z. Q., Yao, Y. X., Qiu, L. F., and Li, Z. X. (2009). A new species of Trissolcus (Hymenoptera: Scelionidae) parasitizing eggs of Halyomorpha halys (Heteroptera: Pentatomidae) in China with comments on its biology. Ann. Entomol. Soc. Am. 102, 39-47. doi: 10.1603/008.102.0104

Zhang, Y. Z., Si, S. L., Zheng, J. T., Li, H. L., Fang, Y., Zhu, C. D., et al. (2011). DNA barcoding of endoparasitoid wasps in the genus Anicetus reveals high levels of host specificity (Hymenoptera: Encyrtidae). Biol. Contr. 58, 182-191. doi: 10.1016/j.biocontrol.2011.05.006

Zhong, Y. Z., Zhang, J. P., Ren, L. L., Tang, R., Zhan, H. X., Chen, G. H., et al. (2017). Behavioral responses of the egg parasitoid Trissolcus japonicus to volatiles from adults of its stink bug host, Halyomorpha halys. J. Pest. Sci. 90, 1097-1105. doi: 10.1007/s10340-017-0884-6

Zuur, A. F., Ieno, E. N., Walker, N. J., Saveliev, A. A., and Smith, G. M. (2009). Mixed effects models and extensions in ecology with R. (New York: Springer).

Conflict of Interest Statement: The authors declare that the research was conducted in the absence of any commercial or financial relationships that could be construed as a potential conflict of interest.

Copyright (c) 2019 Bertoldi, Rondoni, Brodeur and Conti. This is an open-access article distributed under the terms of the Creative Commons Attribution License (CC BY). The use, distribution or reproduction in other forums is permitted, provided the original author(s) and the copyright owner(s) are credited and that the original publication in this journal is cited, in accordance with accepted academic practice. No use, distribution or reproduction is permitted which does not comply with these terms. 